\title{
Ureido Functionalization through Amine-Urea Transamidation under Mild Reaction Conditions
}

\author{
Natalia Guerrero-Alburquerque ${ }^{1,2}$, Shanyu Zhao ${ }^{1}$, Daniel Rentsch ${ }^{3} \mathbb{D}$, Matthias M. Koebel ${ }^{1}$, Marco Lattuada ${ }^{2}$ \\ and Wim J. Malfait 1,*
}

1 Laboratory for Building Energy Materials and Components, Swiss Federal Laboratories for Materials Science and Technology, Empa, Überlandstrasse 129, 8600 Dübendorf, Switzerland; natalia.guerrero@empa.ch (N.G.-A.); shanyu.zhao@empa.ch (S.Z.); matthias.koebel@empa.ch (M.M.K.)

2 Department of Chemistry, University of Fribourg, Chemin du Musée 9, 1700 Fribourg, Switzerland; marco.lattuada@unifr.ch

3 Laboratory for Functional Polymers, Swiss Federal Laboratories for Materials Science and Technology, Empa, Überlandstrasse 129, 8600 Dübendorf, Switzerland; daniel.rentsch@empa.ch

* Correspondence: wim.malfait@empa.ch; Tel.: +41-58-765-4983

Citation: Guerrero-Alburquerque, N.; Zhao, S.; Rentsch, D.; Koebel, M.M.; Lattuada, M.; Malfait, W.J. Ureido Functionalization through Amine-Urea Transamidation under Mild Reaction Conditions. Polymers 2021, 13, 1583. https://doi.org/ $10.3390 /$ polym 13101583

Academic Editor: Cédric Delattre

Received: 30 March 2021

Accepted: 7 May 2021

Published: 14 May 2021

Publisher's Note: MDPI stays neutral with regard to jurisdictional claims in published maps and institutional affiliations.

Copyright: (c) 2021 by the authors. Licensee MDPI, Basel, Switzerland. This article is an open access article distributed under the terms and conditions of the Creative Commons Attribution (CC BY) license (https:// creativecommons.org/licenses/by/ $4.0 /)$.
Abstract: Ureido-functionalized compounds play an indispensable role in important biochemical processes, as well as chemical synthesis and production. Isocyanates, and $\mathrm{KOCN}$ in particular, are the preferred reagents for the ureido functionalization of amine-bearing compounds. In this study, we evaluate the potential of urea as a reagent to graft ureido groups onto amines at relatively low temperatures $\left(<100{ }^{\circ} \mathrm{C}\right)$ in aqueous media. Urea is an inexpensive, non-toxic and biocompatible potential alternative to KOCN for ureido functionalization. From as early as 1864, urea was the go-to reagent for polyurea polycondensation, before falling into disuse after the advent of isocyanate chemistry. We systematically re-investigate the advantages and disadvantages of urea for amine transamidation. High ureido-functionalization conversion was obtained for a wide range of substrates, including primary and secondary amines and amino acids. Reaction times are nearly independent of substrate and $\mathrm{pH}$, but excess urea is required for practically feasible reaction rates. Near full conversion of amines into ureido can be achieved within $10 \mathrm{~h}$ at $90{ }^{\circ} \mathrm{C}$ and within $24 \mathrm{~h}$ at $80{ }^{\circ} \mathrm{C}$, and much slower reaction rates were determined at lower temperatures. The importance of the urea/amine ratio and the temperature dependence of the reaction rates indicate that urea decomposition into an isocyanic acid or a carbamate intermediate is the rate-limiting step. The presence of water leads to a modest increase in reaction rates, but the full conversion of amino groups into ureido groups is also possible in the absence of water in neat alcohol, consistent with a reaction mechanism mediated by an isocyanic acid intermediate (where the water assists in the proton transfer). Hence, the reaction with urea avoids the use of toxic isocyanate reagents by in situ generation of the reactive isocyanate intermediate, but the requirement to separate the excess urea from the reaction product remains a major disadvantage.

Keywords: urea; amine; ureido; urease; catalyst; non-isocyanate

\section{Introduction}

Mono- and di-substituted ureas are abundant in nature and in polymer production. The ureylene functionality ( $\mathrm{R}-\mathrm{HN}-\mathrm{CO}-\mathrm{NH}-\mathrm{R}$ ) is common in natural compounds ranging from hydantoins [1,2] and diphenylureas [3] to di-alkyl ureas [4,5] and the basis of industrial polyurea production. Ureido-functionalized compounds $\left(\mathrm{R}-\mathrm{NH}-\mathrm{CO}-\mathrm{NH}_{2}\right)$ are well known for their properties and applications in medicinal and biochemistry. Ureido acids such as N-carbamoyl- $\beta$-alanine (3-ureidopropionic acid) exhibit antidiabetic properties [6]. N-Carbamoyl-glycine (hydantoic acid) is an intermediate in the formation of hydantoins [1,7-9], for which the derivatives fosphenytoin and phenytoin are anticonvulsants [10], whereas the derivative allantoin is well known as cancer prophylaxis or skin procollagen [11,12]. GABA (4-ureidobutanoic acid (N-carbamoyl- $\gamma$-aminobutyric acid) is the 
main inhibitory neurotransmitter in the human central nervous system [13]. Carbonylbis(Lmethionine) is used in the synthesis of proinsulin analogs [14]. The derivatives of $\mathrm{N}^{\varepsilon}-\left[\mathrm{N}^{\prime}-(2-\right.$ chloroethyl)carbamoyl]-L-lysine display anti-tumoral activity [15]. Additionally, antibiotic agents such as oxazolidinone can be prepared from N-carbamoylamino alcohols [16], and $\mathrm{N}$-carbamoylaminoacids are useful intermediates in the peptide synthesis [17].

Traditionally, the synthesis of ureido and ureylene materials is carried out by the reaction of amino groups with isocyanates. The most popular reagent for ureido formation is $\mathrm{KOCN}[3,7-9,17-22]$, which displays high reactivity and is used at temperatures from 20 to $100{ }^{\circ} \mathrm{C}$ but is a toxic reagent. There has been a growing interest to find non-isocyanate routes for the synthesis of polyurethane, polyurea and ureido-functionalized materials [23-32]. For non-isocyanate polyurethane synthesis, amine compounds/cyclic carbonates [33-36] and bio-based molecules [37-40] such as fatty acids [41] and vegetable oils [42-46] are of particular interest. For ureido and ureylene formation, urea is a potential green alternative to isocyanates [21,47]. Urea is attractive because it is a non-toxic, abundant reagent, and the synthesis can be carried out in aqueous solutions. However, the reaction of urea with amines is not widely used anymore because of the lower reactivity of urea compared to isocyanates and has not been characterized in depth.

In the past (1800s to 1940s), the transamidation of urea with amines was the default process for substituted ureas and polyurea industrial production $[48,49]$. The reaction was typically carried out at high processing temperatures $\left(>120^{\circ} \mathrm{C}\right)$ by reacting highmolecular-weight diamines or alkanolamines with urea in bulk or in solution [50-55]. These high-temperature processes are still used in industry for making products such as phenylureas [3,4,56-61] used as herbicides and coatings [61-63], polyalkylenureas used for melamine-formaldehyde modification [64] and cycloalkyleneureas produced from 1,2-ethylenediamine or 1,3-propylenediamine and used for easy-care cellulose-containing textiles [64,65]. Recently, ureido functionalization of chitosan, in a low-temperature aqueous process, has enabled the synthesis of high-quality chitosan aerogels $[47,66]$. The ureido-functionalized chitosan aerogels could even be produced by ambient pressure drying, with outstanding mechanical properties, an exceptional feat in the field of biopolymer aerogels [47].

In this study, we evaluate the potential of urea as a reagent to graft ureido groups onto amines (Scheme 1$)$ at relatively low temperatures $\left(<100{ }^{\circ} \mathrm{C}\right)$ in aqueous media.

The reaction can follow two mechanisms: in situ formation of isocyanic acid or urea hydrolysis. The isocyanate route (Scheme 1b) is considered to be the dominant mechanism when the reaction is carried out without catalysts $[67,68]$. The presence of water promotes Reaction B (Scheme 1b), via in situ formation of isocyanic acid (HNCO), through a hydrogen-shuttling mechanism, where the water assists the urea decomposition and favors the proton transfer between its two amino groups, promoting the formation of $\mathrm{HNCO}$ and $\mathrm{NH}_{3}[20,67,68]$. Urea forms HNCO through the decomposition of ammonium cyanate. HNCO then undergoes carbamoylation [20], resulting in a new ureido product [21]. Alternatively, the hydrolysis of isocyanic acid into $\mathrm{NH}_{3}$ and $\mathrm{CO}_{2}$ can occur, but this is not likely because of the high reactivity of isocyanic acid with amines. In aqueous solution, urea hydrolysis (Scheme 1c) may also occur, even in the absence of a catalyst, in which case the reaction is expected to proceed through an addition-elimination mechanism [68]. A nucleophilic water attack occurs on the electrophile carbonyl carbon, followed by a tetrahedral intermediate, then the water transfers hydrogen to an amino group, ending with the release of ammonia and the formation of carbamic acid. This carbamic acid can either react with an amino group to form ureido or decompose to $\mathrm{NH}_{3}$ and $\mathrm{CO}_{2}$. Under our reaction conditions, ureido formation is expected to proceed predominantly through an isocyanic acid intermediate formed in situ from the decomposition of urea (Scheme 1b) [21,67,68]. 
(a)



(c)



Scheme 1. (a) General reaction of a primary amine with urea at $80{ }^{\circ} \mathrm{C}$ in aqueous solution to form a ureido product, (b) mechanism of amine with urea reaction via in situ formation of isocyanic acid in aqueous solution, and (c) mechanism of amine with urea reaction via urea hydrolysis.

In this study, we investigate the advantages and disadvantages of urea as a reagent for ureido formation for a range of substrates and synthesis parameters, including $\mathrm{pH}$, solvent composition (aqueous and non-aqueous media), temperature, time, reagent concentration and molecular ratios. The reaction progress is monitored by NMR spectroscopy. We found that amino to ureido conversion close to $100 \%$ is possible in a reasonable time frame for a wide variety of amino-functionalized molecules, provided that the reaction is carried out with a large excess of urea.

\section{Experimental Section}

\subsection{Materials}

Ethanolamine $\geq 98 \%$, hexamethylenediamine $98 \%$, bis-(hexamethylene)triamine high purity $\geq 94 \%$, 5-amino-1-pentanol 95\%, N, $\mathrm{N}^{\prime}$-dimethyl-1,3-propanediamine $97 \%$, glycine $\geq 99 \%$, pyrrole $98 \%$, urea BioXtra, dibutyltin dilaurate (DBTL) $95 \%$, 1,4-diazabicyclo [2.2.2] octane (DABCO) $\geq 99 \%$, p-toluenesulfonic acid (p-TSA) $\geq 98.5 \%$, triethylamine (TEA) $\geq 99 \%$, aluminum acetylacetonate $\left(\mathrm{Al}(\mathrm{acac})_{3}\right) 99 \%$, urease from Canavalia ensiformis (Jack bean), Type IX, powder, 50,000-100,000 units/g solid, 4-(2-hydroxyethyl)-1piperazineethanesulfonic acid (HEPES) $\geq 95 \%$ (titration) and 4-morpholineethanesulfonic acid (MES) were all purchased from Sigma-Aldrich (Buchs, Switzerland). Deuterium oxide $(99.9 \%)$ was obtained from Cambridge Isotope Laboratories. $\mathrm{pH}$ buffer solutions $(\mathrm{pH}=4$, $7,9)$ for $\mathrm{pH}$ meter calibration were purchased from Metrohm (Herisau, Switzerland). All reagents were used without prior purification.

\subsection{Synthesis}

Systematic parameter studies were undertaken to determine the effect of reaction conditions (reagent concentrations, $\mathrm{pH}$, temperature) on the amine-to-ureido conversion. The study focuses on a series where 1 parameter is varied at a time to allow for a direct interpretation of the results and simplify the kinetic modeling, rather than a design of experiments that could find the reaction optimum with fewer experiments but results in a dataset that is harder to interpret. The substrates (Table 1) were selected to include a wide range of chemical structures but with the added criterion of low toxicity and relatively 
low molecular weight to ease the quantitative interpretation of the NMR data. Taking ethanolamine as a model sample, we describe a typical synthesis prepared from a $3 \%$ to $3.7 \%$ $v / v$ ethanolamine solution with urea/ethanolamine in a molar ratio of 6:1. Preparations from other concentrations and molecules are summarized in Section S1 (Table S1). Typically, samples were prepared in glass vials by dissolving $2.980 \mathrm{~g}(49.6 \mathrm{mmol})$ of urea in $9 \mathrm{~mL}$ of distilled water and $1 \mathrm{~mL}$ of deuterated water $\left(10 \% \mathrm{D}_{2} \mathrm{O}\right.$ was added for recording NMR with a lock on the ${ }^{2} \mathrm{H}$ frequency). After urea dissolution, $0.5 \mathrm{~mL}(8.3 \mathrm{mmol})$ of ethanolamine was added to $13.2 \mathrm{~mL}$ of urea solution, and the samples were kept at a constant temperature (typically $80^{\circ} \mathrm{C}$ or a different temperature when the effect of temperature was investigated) for $48 \mathrm{~h}$ under constant stirring $(\approx 250 \mathrm{rpm})$. Aliquots were taken at different times to determine sample compositions by ${ }^{1} \mathrm{H}$ and ${ }^{13} \mathrm{C}$ NMR spectroscopy. For the experiments varying the $\mathrm{pH}$ in the solution, $\mathrm{HCl}$ or $\mathrm{NaOH}$ solutions were added until the target $\mathrm{pH}$ value was achieved. The synthesis experiments for the catalyst screening effort are shown in the Supplementary Materials (Section S2, Table S2). Unless explicitly stated otherwise, all data presented in this manuscript are derived from uncatalyzed experiments.

\subsection{Characterization}

The $\mathrm{pH}$ was monitored at room temperature $\left(20^{\circ} \mathrm{C}\right)$ using $\mathrm{pH}$ strips with a precision of \pm 0.5 or using a $\mathrm{pH}$ meter ( $827 \mathrm{pH}$ Lab from Metrohm (Herisau, Switzerland)) reported with a precision of 0.1 equipped with a flat-membrane electrode. The $\mathrm{pH}$ meter was calibrated in advance for every experiment, using a multi-point calibration with buffers of $\mathrm{pH} 4,7$ and 9 at $20^{\circ} \mathrm{C}$ under stirring. After the calibration, the samples were measured twice at the same temperature and stirring conditions as the calibration. ${ }^{1} \mathrm{H}$ and ${ }^{13} \mathrm{C}$ NMR spectra were obtained using a $5 \mathrm{~mm}$ CryoProbe ${ }^{\mathrm{TM}}$ Prodigy probe equipped with z-gradient on a Bruker Advance III system with a wide-bore $9.4 \mathrm{~T}$ magnet, corresponding to Larmor frequencies of $400.2 \mathrm{MHz}$ for ${ }^{1} \mathrm{H}$ and $100.6 \mathrm{MHz}$ for ${ }^{13} \mathrm{C}$. NMR samples were prepared in $10 \% \mathrm{D}_{2} \mathrm{O} / \mathrm{H}_{2} \mathrm{O} v / v$ solutions. The $1 \mathrm{D}$ NMR experiments were performed at $298 \mathrm{~K}$ using the Bruker standard pulse programs and parameter sets applying $8(30)^{\circ}$ pulse lengths of 1.0 (3.3) $\mu$ s and relaxation delays of 4 (1) s, and 16 (512) scans were accumulated for ${ }^{1} \mathrm{H}\left({ }^{13} \mathrm{C}\right)$ NMR data. Under these conditions, ${ }^{1} \mathrm{H}$ NMR intensities are quantitative, but ${ }^{13} \mathrm{C}$ NMR intensities are affected by incomplete relaxation. The sample compositions of aliquots of the reaction solution were monitored by ${ }^{1} \mathrm{H} \mathrm{NMR}$, and the conversion was quantified by comparing the ratio of the integrated ${ }^{1} \mathrm{H}$ NMR signal of the methylene group(s) adjacent to the amine $\left(I_{x}\right)$ or ureido $\left(I_{y}\right)$ group, according to Equation (1):

$$
N M R \text { conversion }=\frac{I_{x}}{I_{x}+I_{y}}
$$

The NMR spectra are shown in the Supplementary Materials (Sections S3, S7 and S8).

\subsection{Kinetic Modeling}

In order to better understand the kinetics of ureido formation, we developed a kinetic model, aiming at quantitatively accounting for the consumption of urea, the formation of ureido and the change in $\mathrm{pH}$. The equations used have been reported in the Supplementary Materials (Section S9). The model takes into account all reactions in the mechanism of Scheme 1: the reversible decomposition of urea into ammonia and isocyanic acid and the reaction of isocyanic acid with and amine, as well as the decomposition of isocyanic acid to carbon dioxide and ammonia. In addition, the $\mathrm{pH}$ of the solution is computed by accounting for the acid-base equilibria of the amine, the ammonia, the isocyanic acid and the carbonic acid generated by the decomposition of isocyanic acid, with the caveat that $\mathrm{pH}$ is poorly defined in ethanol. Most of the kinetic constants for these reactions were found in the literature. The one constant that has been obtained from the experimental data is the reaction rate of isocyanic acid. 
Table 1. Reactants, products and conversion of amine starting material after a $24 \mathrm{~h}$ reaction time at $80^{\circ} \mathrm{C}$.



* The NMR conversion at $24 \mathrm{~h}$ cannot be calculated from the NMR spectra because of the precipitation of the product(s). The ureido functionalization ( $\left.\mathrm{R}-\mathrm{NH}-\mathrm{CO}-\mathrm{NH}_{2}\right)$ was $43.2 \%$ after $8 \mathrm{~h}$, in line with the other amines (Figure 2). The possibility for a continued conversion beyond $8 \mathrm{~h}$ of amine into ureido is corroborated by the absence of detectable unreacted hexamethylenediamine in the $24 \mathrm{~h}$ aliquot. ${ }^{* *}$ The ureido conversion on the primary amines of bis-(hexamethylene)triamine approaches $100 \%$ at $24 \mathrm{~h}$, hence possible products with one or two unreacted primary amines are not considered. The conversion of 1,1'-(azanediylbis(hexane-6,1-diyl))diurea and 1,1'-(azanediylbis(hexane-6,1-diyl))diurea can then be calculated directly from the NMR conversion of ureido modification on the secondary amine.

\section{Results and Discussion}

\subsection{Ureido Formation}

\subsubsection{Effect of the Substrate}

A variety of amines was studied to evaluate the feasibility of forming ureido groups by reaction with urea (Table 1 ). The reaction progress was followed by ${ }^{1} \mathrm{H}$ and ${ }^{13} \mathrm{C}$ NMR for ethanolamine (Figure 1a,b, respectively). The NMR spectra for the other substrates can be found in the Supplementary Materials (Sections S3 and S10). Both the ${ }^{1} \mathrm{H}$ and ${ }^{13} \mathrm{C}$ NMR indicate a progressive conversion of ethanolamine into 2-hydroxyethyl urea with 
increasing reaction times, with almost no detectable ethanolamine after $46 \mathrm{~h}$ of reaction. Because urea is used in large excess, significant quantities of unreacted urea remain in the reaction mixture.
<smiles>NC(N)=O</smiles><smiles>NCCO</smiles>

ethanolamine<smiles>NC(=O)NCCO</smiles>

2-hydroxyethyl urea

Figure 1. (a) ${ }^{1} \mathrm{H}$ NMR spectra and (b) ${ }^{13} \mathrm{C}$ NMR spectra of the formation of 2-hydroxyethyl urea from ethanolamine and urea. The reaction was conducted at $80{ }^{\circ} \mathrm{C}$ with $5 \% v / v$ of ethanolamine in $\mathrm{H}_{2} \mathrm{O} / \mathrm{D}_{2} \mathrm{O}$ and an ethanolamine/urea ratio of 1:6. The times on the right of each spectrum indicate the reaction time. Spectra are offset vertically for clarity. Note that the ${ }^{13} \mathrm{C}$ peak for $\mathrm{c}^{\prime}$ is broadened significantly, hence the lower peak height.

Except for pyrrole, the conversion rates (determined by ${ }^{1} \mathrm{H}$ NMR) were found to be similar for all amines, independent of the substrate, with high ureido conversion $(>90 \%$ after $24 \mathrm{~h}$ ) (Figure 2, Table S1). Presumably, the lack of reactivity for pyrrole is because the nitrogen's lone electron pair is part of the aromatic system. For hexamethylenediamine, data are only available up to $8 \mathrm{~h}$ because of the formation of a white precipitate for longer reaction times. Note that the reaction product of glycine and urea, hydantoic acid (ncarbamoyl-glycine), the precursor of hydantoins and derivatives [69], was also highly formed within $24 \mathrm{~h}$. The effect of substrate on the reaction kinetics is modeled in detail in Section 3.5.

The case of hexamethylenediamine $\left(80^{\circ} \mathrm{C}, 5 \% \mathrm{v} / \mathrm{v}\right.$ hexamethylenediamine in $\mathrm{H}_{2} \mathrm{O} / \mathrm{D}_{2} \mathrm{O}$, urea/hexamethylenediamine: 12:1) is presented in more detail (Figure 3). The reaction of urea with hexamethylenediamine generates two products. First, one of the primary amines reacts with urea to yield (6-aminohexyl)urea (Scheme 2a). The remaining free amino group of this first reaction product can then react with another urea to yield 1,1'(hexamethylene)diurea (Scheme 2b). 




- N,N'-dimethyl-1,3-propanediamine
- Ethanolamine
5-amino-1-pentanol
- Glycine
- Hexamethylenediamine
- Bis-(hexamethylene)triamine - primary amine
Bis-(hexamethylene)triamine - secondary amine

Figure 2. Ureido NMR conversion as a function of reaction time for different substrates. The reactions were conducted at $80{ }^{\circ} \mathrm{C}$ with $5 \% v / v$ of the amine molecule in $\mathrm{H}_{2} \mathrm{O} / \mathrm{D}_{2} \mathrm{O}$ and with a 6-fold urea excess: ethanolamine/urea $=1: 6 ; 5$-amino-1-pentanol/urea $=1: 6$; hexamethylenediamine/urea $=1: 6 ; \mathrm{N} ; \mathrm{N}^{\prime}$-dimethyl-1;3-propanediamine/urea = 1:12; bis-(hexamethylene)triamine $/$ urea $=1: 18$; glycine $/$ urea $=1: 6$; pyrrole / urea $=1: 6$.

Thus, there are three products to take into consideration. In the ${ }^{13} \mathrm{C}$ NMR spectra, the resonance at 25.92 is assigned to the midchain methylene groups at Positions $C$ and D of the chain of the starting material The set of resonances near $25.8 \mathrm{ppm}$ shifted from each other by $0.05 \mathrm{ppm}$ can be attributed to the same methylenes when only one of the amines has reacted with urea to form (6-aminohexyl)urea. Here, the central methylenes ( $c^{\prime}$ and $d^{\prime}$, Figure 3b) give rise to two peaks because the molecule is no longer symmetric. Finally, the last resonance at $25.69 \mathrm{ppm}$ is assigned to the same central methylenes ( $c^{\prime \prime}$ and $\left.\mathrm{d}^{\prime \prime}\right)$ when both amines have reacted to form $1,1^{\prime}$-(hexamethylene)diurea. The signal associated with the first product rapidly increases, followed by much slower increases of the signal from the second product (Figure 3c). After 8 to $12 \mathrm{~h}$, the product started to precipitate, and no more aliquots were analyzed. The theoretically expected change in concentration of hexamethylenediamine, (6-aminohexyl)urea and 1,1'-(hexamethylene)diurea was predicted using Monte Carlo simulations for various probability ratios for Reaction B over Reaction A (Scheme 2) (Figure 3d, Section S4). Experimentally, more (6-aminohexyl)urea and less 1,6-(hexamethylene)diurea are formed than expected for an equal probability ratio, and the experimental results are consistent with a probability ratio of 0.6. Thus, the prior grafting of an ureido group on one end of hexamethylenediamine hinders ureido grafting on the other side of the molecule. This is also confirmed by the kinetic modeling of the NMR conversions (Section 3.5 and Section S9), from which a 50\% reduction in reactivity is deduced. 
a)



c)





d)



Figure 3. (a) Reactant and products of hexamethylenediamine/urea reaction. (b) ${ }^{13} \mathrm{C}$ NMR spectra: the spectra were aligned, and the $\mathrm{c}+\mathrm{d}$ resonance is located at 25.9. (c) NMR integrals as a function of time: the fitted lines correspond to the results of the kinetic modeling (see Section 3.5). (d) Experimental (markers) and modeled (lines) concentrations of hexamethylenediamine: (6-aminohexyl)urea and 1,6-(hexamethylene)diurea as a function of reaction progress. The numbers on the right denote the probability ratio for Reaction B over Reaction A (Scheme 2) (see Figure 3d) (thickest line denotes equal probabilities).<smiles>CCCCCCN</smiles>

(a)<smiles>NCCCCCCNC(N)=O</smiles>

(b)

Scheme 2. Reaction of hexamethylenediamine and urea to form: (a) (6-aminohexyl)urea and (b) 1,1-bis(6-ureidohexyl)urea.

\subsubsection{Effect of the Temperature}

Temperature plays an important role in the formation of the isocyanic acid and the hydrolysis of the urea. Several studies investigated amine/urea at reaction temperatures above $100^{\circ} \mathrm{C}[21,49,55,70]$. Above, we demonstrated that the reaction can be performed at lower temperatures for a wide range of substrates (Figure 2). Here, we investigate the 
effect of temperature more closely, using ethanolamine/urea as a model system (Figure 4, Section S7). There is a strong, non-linear effect of temperature, and a big increase in the ureido functionalization can be observed at $80^{\circ} \mathrm{C}$. At temperatures, $\geq 80^{\circ} \mathrm{C}$ the conversion of the primary amine-to-ureido group was estimated to be $>99 \%$ after $48 \mathrm{~h}$. At lower temperatures, the NMR conversions are smaller and longer reaction times are required for full conversion. The effect of temperature on the reaction kinetics are modeled in detail in Section 3.5.

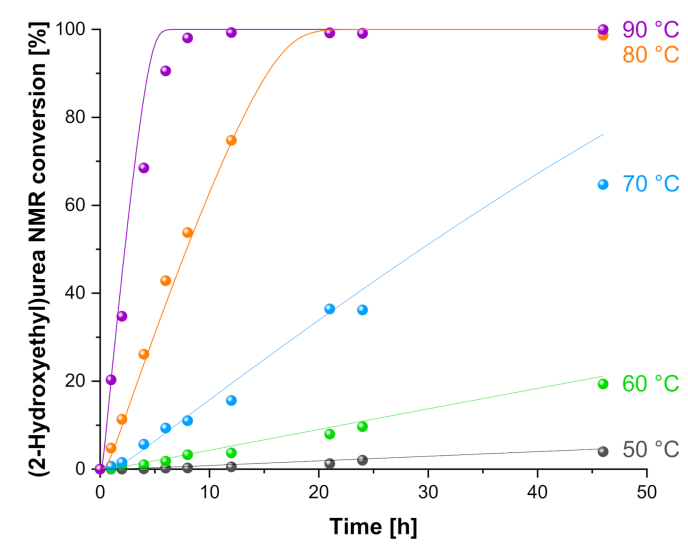

Figure 4. Time-dependent formation of (2-hydroxyethyl)urea as a function of reaction temperature. The reactions were conducted with $5 \% v / v$ of ethanolamine in $\mathrm{H}_{2} \mathrm{O} / \mathrm{D}_{2} \mathrm{O}$ with a 6-fold excess of urea (ethanolamine/urea $=1: 6$ ). The fitted lines correspond to the results of the kinetic modelling (see Section 3.5).

\subsubsection{Effect of Urea: Ethanolamine Ratio and $\mathrm{pH}$}

Excess urea strongly increases the conversion to ureido (Figure 5). As the reaction liberates ammonia, the increased conversion for higher urea/ethanolamine ratios in theory could be an effect of $\mathrm{pH}$ (Table S1). However, a systematic study of the effect of $\mathrm{pH}$ indicates only moderate dependence of the NMR conversion on $\mathrm{pH}$ from 1 to 12 . The NMR conversions strongly decrease for an initial $\mathrm{pH}$ above 12 (Section S5, Figure S7). Hence, the strong effect of the urea/ethanolamine ratio on amine-to-ureido conversion is not related to a change in $\mathrm{pH}$ but rather an indication that urea is the limiting reactant and, hence, urea decomposition the rate-limiting process. This is also confirmed by the kinetic modeling in Section 3.5. The need to use a large excess of urea is a major disadvantage as it complicates isolation and purification of the product after reaction.



Figure 5. Formation of (2-hydroxyethyl)urea as a function of urea/ethanolamine ratio from 0.5:1 to 6:1. The reactions were carried out with $2 \%$ and $5 \% v / v$ concentrations of ethanolamine in $\mathrm{H}_{2} \mathrm{O} / \mathrm{D}_{2} \mathrm{O}$ (product composition determined after $48 \mathrm{~h}$ at $80^{\circ} \mathrm{C}$ ). 


\subsubsection{Effect of Ethanol as Solvent and Co-Solvent}

A series of experiments with different proportions of water/ethanol was conducted to evaluate the feasibility to carry out the transamidation in a non-aqueous solution rather than water (Figure 6, Section S8). The ethanolamine/urea reaction takes place even in neat ethanol, with near $100 \%$ ureido functionalization after $24 \mathrm{~h}$ and $80^{\circ} \mathrm{C}$, but the reaction does progress somewhat faster when the reaction is carried out in solvents with higher water content. Both the isocyanate and hydrolysis reaction mechanisms (Reactions B and $\mathrm{C}$ and Scheme 1) involve water. Water is obviously important for hydrolysis, and water is known to favor the formation of isocyanic acid and ammonia because of its assistance to the proton transfer between the amines of the urea [67]. The moderate dependence on water content indicates that water does promote the reaction, but it is not a requirement (as it would be for hydrolysis), consistent with an isocyanic acid intermediate as the dominant reaction mechanism under our experimental conditions.



Figure 6. (2-hydroxyethyl)urea NMR conversion as a function of the water content of the ethanolwater mixture at different reaction times. The reactions were conducted with $5 \% v / v$ of ethanolamine and a 6-fold urea excess (ethanolamine/urea $=1: 6$ ) at $80^{\circ} \mathrm{C}$.

\subsection{Ureylene Formation}

In a long-term experiment (114 days at $80^{\circ} \mathrm{C}$ with an ethanolamine/urea ratio of 2:1, i.e., with a factor of two excess of ethanolamine if only ureido formation is considered), no significant amount of $\mathrm{N}, \mathrm{N}^{\prime}$-bis-(hydroxyethyl)urea was observed by NMR spectroscopy: half of the ethanolamine converted into (2-hydroxyethyl)urea, but the remainder did not react, even for very long reaction times. Thus, ureylene does not form in substantial quantities under these reaction conditions, even for the longest reaction times. However, a qualitative HPLC-MS (ESI positive mode, data not shown) measurement did detect a signal at $m / z$ of 149.2 , consistent with protonated $\mathrm{N}, \mathrm{N}^{\prime}$-bis-(hydroxyethyl)urea. Hence, the formation of traces of ureylene is likely but not in sufficient quantities to be of further interest within this study. In order to effectively form ureylene linkages, e.g., di-substituted ureas or polyurea, from (poly)amines and urea, the high-temperature processes established by the older patent studies in the literature $[3-5,48,52,53]$ remain necessary. 


\subsection{Effect of Catalysts}

The effect of catalysts on the reaction of ethanolamine with urea was investigated with the aim of accelerating ureido formation and, potentially catalyzing ureylene formation (Section S6). Because possible ureylene formation was a target, these catalyst experiments were carried out with an ethanolamine/urea ratio of 1:0.5, i.e., the stoichiometric ratio for ureylene formation. Note that due to this lack of excess urea, the ureido conversion is generally lower compared to the previous experiments under the same conditions but with a six-fold excess of urea (Figure 5). In these catalyst screening series, a variety of well-known catalysts from the polyurethane industry was first selected, e.g., dibutyltindilaurate (DBTL) [71], 1,4-diazabicyclo[2.2.2] octane (DABCO) [72], triethylamine (TEA) [73], aluminum acetylacetonate [74] $\left(\mathrm{Al}(\mathrm{acac})_{3}\right)$ or p-toluene sulfonic acid (p-TSA) [75], where the latter is used specifically for polyurea. In the preparation of the samples, it often was difficult to find a solvent suitable for both urea and the catalyst. A mixture of $90 \% \mathrm{H}_{2} \mathrm{O}$ and $10 \% \mathrm{D}_{2} \mathrm{O}$ could be used for DABCO and p-TSA, but in the case of DBTL, TEA, and $\mathrm{Al}(\mathrm{acac})_{3}$, a mixture of $90 \%$ methanol $(\mathrm{MeOH})$ and $10 \%$ deuterated methanol $\left(\mathrm{CD}_{3} \mathrm{OD}\right)$ had to be used due to the incompatibility of these catalysts in aqueous media. Because of the lower boiling point, the reaction was carried out at $60^{\circ} \mathrm{C}$, with negative effects on ureido conversion (Figure 4).

Despite the overall low NMR conversions, the direct comparison between the experiments with and without catalyst, but under otherwise identical conditions, revealed minor increases in NMR conversion with the catalyst addition to a minor extent: from $25.1 \%$ to $29.4 \%$ with DABCO, from $25.1 \%$ to $26.2 \%$ with p-TSA, from $2.2 \%$ to $13.7 \%$ with DBTL, from $2.2 \%$ to $7.65 \%$ with TEA and from $2.2 \%$ to $8.7 \%$ with $\mathrm{Al}(\mathrm{acac})_{3}$. In addition to the lackluster performance of accelerated ureido formation, no ureylene formation was observed for any of the catalysts. Thus, because of solvent compatibility issues and at the best moderate increases in ureido formation, no practical benefits could be derived from this set of catalysts.

Given the indications that urea decomposition is a rate-limiting step (Figure 5 and Section 3.5), we then turned to a catalyst that could accelerate ureido formation through the hydrolysis mechanism. Thus, urease was evaluated due to its high efficiency in promoting the hydrolysis of urea [76-78]. For example, urease has been applied to promote the formation of strong chitosan/urea gels $[79,80]$. The initial synthesis was carried out without $\mathrm{pH}$ adjustment, meaning high $\mathrm{pH}$ values around $10-11$, and no catalytic activity was observed, i.e., no ureido or ureylene formation. In a second series of experiments, a buffer (HEPES) was used to adjust the $\mathrm{pH}$ to ranges more compatible with urease activity. This buffer was selected because it was reported to not strongly inhibit the urease activity [81]. The $\mathrm{pH}$ of the ethanolamine solution could be adjusted to the optimum $\mathrm{pH}$ of 7-8 for urease [81], but only when the buffer concentration was very high, well beyond the range where it was shown to not affect urease activity. Again, no ureido or ureylene formation was observed, most likely because of the very high buffer content. In summary, no catalysts to accelerate ureido formation or enable ureylene formation under our mild reaction conditions were identified.

\subsection{Advantages and Disadvantages of Urea Compared to KOCN for Ureido Formation}

Ureido formation from the reaction of urea with amines has distinct advantages and disadvantages. The main advantages are (i) the non-toxicity, biocompatibility, low cost and availability of urea as a feedstock; (ii) the high conversion with a wide range of amine substrates; (iii) the compatibility with water and ethanol as a solvent system; and (iv) the relatively mild reaction conditions $\left(<100^{\circ} \mathrm{C}\right.$, atmospheric pressure, no catalyst, wide range of $\mathrm{pH}$ values). These advantages are particularly relevant for chitosan aerogel production: the biopolymer aerogel field experiences a strong trend toward eliminating toxic crosslinkers, e.g., aldehydes in the case of chitosan aerogels [47,66,82]. The main downsides are (i) relatively low reaction rates (ca. 10 and $24 \mathrm{~h}$ ) are required to reach close to $100 \%$ conversion at 80 and $90^{\circ} \mathrm{C}$, respectively, and (ii) the requirement for excess urea to accelerate 
the reaction, i.e., the requirement for isolation/separation after synthesis. Particularly the need for separation is a major disadvantage of the reaction. For comparison, isocyanates, with KOCN in particular, are currently the most widely used reagents to produce ureidofunctionalized compounds from amines. The main advantage of KOCN over urea is the higher reactivity, hence shorter reaction times, hence the ability to carry out the reaction at temperatures between 20 and $100{ }^{\circ} \mathrm{C}$. However, $\mathrm{KOCN}$ is toxic and harmful and, despite the higher reactivity, most often is also used in excess, e.g., at a $\mathrm{KOCN} /$ amine ratio of 2.2:1 [83], 97.1:1 [84] or 1.3:1 [85]. During the reaction with urea, toxic isocyanic acid is also formed but only in situ as a reactive intermediate. Due to the slow decomposition of urea and the high reactivity of the isocyanic acid (see below), which rapidly undergoes nucleophilic addition of amines or hydrolysis, the effective concentration of this intermediate remains low.

\subsection{Kinetic Modeling of Uncatalyzed Reactions}

The results of the kinetic modeling (Section 2.4 and Section S9) show that the reaction rate of isocyanic acid with amines is very high, several orders of magnitude higher than the rate of decomposition of urea, which is clearly the rate-determining step. The model is able to predict how the $\mathrm{pH}$ for most amines decreases (Figure S23), even though only slightly, during the reaction. The exception is the reaction with glycine, which, as an amino acid, starts at a low $\mathrm{pH}$, with the production of ammonia, increasing it progressively. The model does a good job in quantitatively describing the conversion in ureido compounds as a function of temperature (Figure 4) and for the different substrates (Figure S24). The model also catches the major changes in $\mathrm{pH}$ as a function of time and temperature (Figure S25). Some deviations between model and experiment are observed for the $\mathrm{pH}$, partially due to the experimental uncertainty in measured $\mathrm{pH}$, and in part due to the presence of urea in solution, which, at the relatively high concentration used in the experiments, alters the ionic equilibria. This is a known effect, especially in the case of water [86], but is very difficult to be quantitatively accounted for. In addition, the glass vials were opened repeatedly to take the aliquots, enabling ammonia and $\mathrm{CO}_{2}$ exchange with air.

\section{Conclusions}

We demonstrate that urea is a viable alternative to isocyanates to produce ureidofunctionalized compounds through a lower temperature variation of a largely forgotten high-temperature process between amines and their transamidation with urea. Urea is an inexpensive, green, non-toxic and biocompatible reagent compared to toxic isocyanates. The study revealed the possibility to synthesize ureido groups using a variety of amine substrates, including amino acids and primary and secondary amines. The reaction conditions are relatively mild: $80-90^{\circ} \mathrm{C}$, atmospheric pressure, insensitive to $\mathrm{pH}$ over a broad range. Excess urea is required to limit the reaction times to practically relevant durations, and the required separation is the main drawback of the reaction. The reaction rates display a strong, non-linear temperature dependence with a strong increase in reaction rates above $70{ }^{\circ} \mathrm{C}$, consistent with urea decomposition as the rate-limiting step. The presence of water in the solvent system increases the reaction rate to a minor extent but is not essential to obtain high NMR conversions, and the reaction can also be carried with close to $100 \%$ conversion within $24 \mathrm{~h}$ in absolute ethanol. The modest dependence of reaction rates on water content supports the hypothesis that a mechanism with an isocyanic acid intermediate is the dominant reaction mechanism rather than a process mediated by urea hydrolysis. The transamidation reaction is similar to the standard reaction of amines with $\mathrm{KOCN}$, but toxic isocyanate is generated in situ as a reactive intermediate. The use of some common catalysts moderately increased the conversion but has no practical relevance, also because of solvent/solubility compatibility issues. Even in the absence of catalysts, high NMR conversions of $>95 \%$ can be achieved within $6 \mathrm{~h}$ at $90{ }^{\circ} \mathrm{C}$ and full conversion within $20 \mathrm{~h}$ at $80^{\circ} \mathrm{C}$.

Supplementary Materials: The following are available online at https:/ /www.mdpi.com/article/10 .3390/polym13101583/s1, Figures S1-S29, Tables S1-S3. 
Author Contributions: Conceptualization, N.G.-A., W.J.M., M.M.K. and S.Z.; methodology, N.G.-A., D.R., M.L., W.J.M. and S.Z.; software, N.G.-A.; validation, N.G.-A. and W.J.M.; formal analysis, N.G.-A., M.L. and W.J.M.; investigation, N.G.-A.; resources, W.J.M. and D.R.; data curation, N.G.-A., W.J.M.; writing — original draft preparation, N.G.-A. and W.J.M.; writing—review and editing, S.Z., D.R., M.L., M.M.K.; visualization, N.G.-A. and W.J.M.; supervision, W.J.M., S.Z., M.L. and M.M.K.; project administration, W.J.M.; funding acquisition, W.J.M. All authors have read and agreed to the published version of the manuscript.

Funding: This study was supported by the Swiss National Science Foundation through Grant SNF200021_179000 (W.J.M.). The NMR spectrometer was funded in part by Grant 150638 from the Swiss National Science Foundation (D.R.).

Institutional Review Board Statement: Not applicable.

Informed Consent Statement: Not applicable.

Data Availability Statement: Data is available in the Supplementary Materials and from the corresponding author on request.

Acknowledgments: We thank Lukasz Kufel for his assistance with laboratory work and Norbert Heeb for the HPLC-MS measurements.

Conflicts of Interest: The authors declare no conflict of interest.

\section{References}

1. Urech, F. XXI. Ueber Lacturaminsäure und Lactylharnstoff. Justus Liebig's Ann. Chem. Pharm. 1873, 165, 99-103. [CrossRef]

2. Konnert, L.; Lamaty, F.; Martinez, J.; Colacino, E. Recent Advances in the Synthesis of Hydantoins: The State of the Art of a Valuable Scaffold. Chem. Rev. 2017, 117, 13757-13809. [CrossRef] [PubMed]

3. Davis, T.L.; Blanchard, K.C. PHENYLUREA and sym.-DIPHENYLUREA. Org. Synth. 1923, 3, 95.

4. Davis, T.L. Di-Alkyl Urea. U.S. Patent 1,785,730, 23 December 1930. pp. 3-4.

5. Erickson, J.G. Reactions of Long-chain Amines. II. Reactions with Urea1. J. Am. Chem. Soc. 1954, 76, 3977-3978. [CrossRef]

6. Theis, S.; Hartrodt, B.; Kottra, G.; Neubert, K.; Daniel, H. Defining minimal structural features in substrates of the H(+)/peptide cotransporter PEPT2 using novel amino acid and dipeptide derivatives. Mol. Pharmacol. 2002, 61, 214-221. [CrossRef]

7. McMeekin, T.L.; Cohn, E.J.; Weare, J.H. Studies in the Physical Chemistry of Amino Acids, Peptides and Related Substances. III. The Solubility of Derivatives of the Amino Acids in Alcohol-Water Mixtures. J. Am. Chem. Soc. 1935, 57, 626-633. [CrossRef]

8. Stella, V.; Higuchi, T. Kinetics of the acid-catalyzed closure of hydantoic acids. Effect of 2-aryl and 2-alkyl substituents. J. Org. Chem. 1973, 38, 1527-1534. [CrossRef]

9. Crosby, O. Urech hydantoin synthesis. In Catalysis from A to Z; Wiley-VCH Verlag GmbH \& Co. KGaA: Weenheim, Germany, 2020; pp. 2856-2859.

10. Löscher, W.; Reissmüller, E.; Ebert, U. Anticonvulsant effect of fosphenytoin in amygdala-kindled rats: Comparison with phenytoin. Epilepsy Res. 1998, 30, 69-76. [CrossRef]

11. Scimeca, J.; Fast, D.; Zimmerman, A. Use of Allantoin as a Pro-Collagen Synthesis agent in Cosmetic Compositions. U.S. Patent Application No. 11/977,926, 28 May 2008.

12. Cativiela, C.; Fraile, J.M.; Garcia, J.I.; Lázaro, B.; Mayoral, J.A.; Pallares, A. Heterogeneous catalysis in the synthesis and reactivity of allantoin. Green Chem. 2003, 5, 275-277. [CrossRef]

13. Wermuth, C.G.; Bourguignon, J.J.; Schlewer, G.; Gies, J.P.; Schoenfelder, A.; Melikian, A.; Bouchet, M.J.; Chantreux, D.; Molimard, J.C. Synthesis and structure-activity relationships of a series of aminopyridazine derivatives of.gamma.-aminobutyric acid acting as selective GABA-A antagonists. J. Med. Chem. 1987, 30, 239-249. [CrossRef]

14. Busse, W.D.; Carpenter, F.H. Synthesis and properties of carbonylbis(methionyl)insulin, a proinsulin analog which is convertible to insulin by cyanogen bromide cleavage. Biochemistry 1976, 15, 1649-1657. [CrossRef]

15. Levit, G.L.; Radina, L.B.; Krasnov, V.P.; Gopko, V.F.; Nikiforova, N.V.; Peretolchina, N.M. Nw-Alkylnitrosocarbamoyl- $\alpha, \omega-$ diaminocarboxylic acids. 3. Synthesis and antitumor activity of $\mathrm{N} \varepsilon$-nitroso- $\mathrm{N} \varepsilon-\left[\mathrm{N}^{\prime}\right.$-(2-chloroethyl)carbamoyl]-L-lysine and $\mathrm{N} \varepsilon$-[N'-(2-chloroethyl)-N'-nitroso-carbamoyl]-L-lysine. Pharm. Chem. J. 1996, 30, 306-309. [CrossRef]

16. Suzuki, M.; Yamazaki, T.; Ohta, H.; Shima, K.; Ohi, K.; Nishiyama, S.; Sugai, T. N-Carbamylamino Alcohols as the Precursors of Oxazolidinones via Nitrosation-Deamination Reaction. Synlett 2000, 2000, 189-192. [CrossRef]

17. Lagrille, O.; Taillades, J.; Boiteau, L.; Commeyras, A. N-Carbamoyl Derivatives and Their Nitrosation by Gaseous NOx-A New, Promising Tool in Stepwise Peptide Synthesis. Eur. J. Org. Chem. 2002, 2002, 1026-1032. [CrossRef]

18. Shimada, N.; Ino, H.; Maie, K.; Nakayama, M.; Kano, A.; Maruyama, A. Ureido-Derivatized Polymers Based on Both Poly(allylurea) and Poly(l-citrulline) Exhibit UCST-Type Phase Transition Behavior under Physiologically Relevant Conditions. Biomacromolecules 2011, 12, 3418-3422. [CrossRef]

19. Delgado, G.E.; Seijas, L.E.; Mora, A.J.; González, T.; Briceño, A. Synthesis, Crystal Structure and Hydrogen-Bonding Patterns in (RS)-1-Carbamoyl Pyrrolidine-2-Carboxylic Acid. J. Chem. Crystallogr. 2012, 42, 388-393. [CrossRef] 
20. Khan, Z.; Rafiquee, M.Z.A.; Kabir-ud-din; Niaz, M.A.; Khan, A.A. Kinetics and mechanism of alkaline hydrolysis of urea and sodium cyanate. Indian J. Chem. Sect. A Inorg. Phys. Theor. Anal. Chem. 1996, 35, 1116-1119.

21. Kravchenko, A.N.; Chikunov, I.E. Chemistry of ureido carboxylic and ureylene dicarboxylic acids. Russ. Chem. Rev. 2006, 75, 191-206. [CrossRef]

22. Berlinerblau, J. Ueber die Einwirkung von Chlorcyan auf Ortho- und auf Para-Amidophenetol. J. Prakt. Chem. 1884, 30, 97-115. [CrossRef]

23. Dennis, J.M.; Steinberg, L.I.; Pekkanen, A.M.; Maiz, J.; Hegde, M.; Müller, A.J.; Long, T.E. Synthesis and characterization of isocyanate-free polyureas. Green Chem. 2017, 20, 243-249. [CrossRef]

24. Shang, J.; Liu, S.; Ma, X.; Lu, L.; Deng, Y. A new route of $\mathrm{CO}_{2}$ catalytic activation: Syntheses of N-substituted carbamates from dialkyl carbonates and polyureas. Green Chem. 2012, 14, 2899-2906. [CrossRef]

25. Kathalewar, M.S.; Joshi, P.B.; Sabnis, A.S.; Malshe, V.C. Non-isocyanate polyurethanes: From chemistry to applications. RSC Adv. 2013, 3, 4110-4129. [CrossRef]

26. Rokicki, G.; Parzuchowski, P.G.; Mazurek, M.M. Non-isocyanate polyurethanes: Synthesis, properties, and applications. Polym. Adv. Technol. 2015, 26, 707-761. [CrossRef]

27. Kébir, N.; Benoit, M.; Legrand, C.; Burel, F. Non-isocyanate thermoplastic polyureas (NIPUreas) through a methyl carbamate metathesis polymerization. Eur. Polym. J. 2017, 96, 87-96. [CrossRef]

28. Bizet, B.; Grau, E.; Cramail, H.; Asua, J.M. Water-based non-isocyanate polyurethane-ureas (NIPUUs). Polym. Chem. 2020, 11, 3786-3799. [CrossRef]

29. Zareanshahraki, F.; Asemani, H.; Skuza, J.; Mannari, V. Synthesis of non-isocyanate polyurethanes and their application in radiation-curable aerospace coatings. Prog. Org. Coat. 2020, 138, 105394. [CrossRef]

30. Vessally, E.; Soleimani-Amiri, S.; Hosseinian, A.; Edjlali, L.; Babazadeh, M. Chemical fixation of $\mathrm{CO}_{2}$ to 2-aminobenzonitriles: A straightforward route to quinazoline-2,4(1H,3H)-diones with green and sustainable chemistry perspectives. J. CO2 Util. 2017, 21, 342-352. [CrossRef]

31. Long, Y.; Zheng, L.; Gu, Y.; Lin, H.; Xie, X. Carbon dioxide adduct from polypropylene glycol grafted polyethyleneimine as a climate-friendly blowing agent for polyurethane foams. Polymer 2014, 55, 6494-6503. [CrossRef]

32. Błażek, K.; Datta, J. Renewable natural resources as green alternative substrates to obtain bio-based non-isocyanate polyurethanesreview. Crit. Rev. Environ. Sci. Technol. 2019, 49, 173-211. [CrossRef]

33. Whelan, J.M.; Hill, M.; Cotter, R.J. Multiple Cyclic Carbonate Polymers. U.S. Patent 3,072,613, 8 January 1963.

34. Asemani, H.; Mannari, V. Synthesis and evaluation of non-isocyanate polyurethane polyols for heat-cured thermoset coatings. Prog. Org. Coat. 2019, 131, 247-258. [CrossRef]

35. Carré, C.; Ecochard, Y.; Caillol, S.; Avérous, L. From the Synthesis of Biobased Cyclic Carbonate to Polyhydroxyurethanes: A Promising Route towards Renewable Non-Isocyanate Polyurethanes. ChemSusChem 2019, 12, 3410-3430. [CrossRef] [PubMed]

36. Karami, Z.; Zohuriaan-Mehr, M.; Rostami, A. Bio-based thermo-healable non-isocyanate polyurethane DA network in comparison with its epoxy counterpart. J. CO2 Util. 2017, 18, 294-302. [CrossRef]

37. Dechent, S.-E.; Kleij, A.W.; Luinstra, G.A. Fully bio-derived $\mathrm{CO}_{2}$ polymers for non-isocyanate based polyurethane synthesis. Green Chem. 2020, 22, 969-978. [CrossRef]

38. Schmidt, S.; Göppert, N.E.; Bruchmann, B.; Mülhaupt, R. Liquid sorbitol ether carbonate as intermediate for rigid and segmented non-isocyanate polyhydroxyurethane thermosets. Eur. Polym. J. 2017, 94, 136-142. [CrossRef]

39. Bähr, M.; Bitto, A.; Mülhaupt, R. Cyclic limonene dicarbonate as a new monomer for non-isocyanate oligo- and polyurethanes (NIPU) based upon terpenes. Green Chem. 2012, 14, 1447-1454. [CrossRef]

40. Esmaeili, N.; Zohuriaan-Mehr, M.; Salimi, A.; Vafayan, M.; Meyer, W. Tannic acid derived non-isocyanate polyurethane networks: Synthesis, curing kinetics, antioxidizing activity and cell viability. Thermochim. Acta 2018, 664, 64-72. [CrossRef]

41. Maisonneuve, L.; More, A.S.; Foltran, S.; Alfos, C.; Robert, F.; Landais, Y.; Tassaing, T.; Grau, E.; Cramail, H. Novel green fatty acid-based bis-cyclic carbonates for the synthesis of isocyanate-free poly(hydroxyurethane amide)s. RSC Adv. 2014, 4, 25795-25803. [CrossRef]

42. Doley, S.; Dolui, S.K. Solvent and catalyst-free synthesis of sunflower oil based polyurethane through non-isocyanate route and its coatings properties. Eur. Polym. J. 2018, 102, 161-168. [CrossRef]

43. Samanta, S.; Selvakumar, S.; Bahr, J.; Wickramaratne, D.S.; Sibi, M.; Chisholm, B.J. Synthesis and Characterization of Polyurethane Networks Derived from Soybean-Oil-Based Cyclic Carbonates and Bioderivable Diamines. ACS Sustain. Chem. Eng. 2016, 4, 6551-6561. [CrossRef]

44. Loulergue, P.; Amela-Cortes, M.; Cordier, S.; Molard, Y.; Lemiègre, L.; Audic, J.-L. Polyurethanes prepared from cyclocarbonated broccoli seed oil (PUcc): New biobased organic matrices for incorporation of phosphorescent metal nanocluster. J. Appl. Polym. Sci. 2017, 134, 45339. [CrossRef]

45. Bähr, M.; Mülhaupt, R. Linseed and soybean oil-based polyurethanes prepared via the non-isocyanate route and catalytic carbon dioxide conversion. Green Chem. 2012, 14, 483-489. [CrossRef]

46. Mahendran, A.R.; Aust, N.; Wuzella, G.; Müller, U.; Kandelbauer, A. Bio-Based Non-Isocyanate Urethane Derived from Plant Oil. J. Polym. Environ. 2012, 20, 926-931. [CrossRef] 
47. Alburquerque, N.G.; Zhao, S.; Adilien, N.; Koebel, M.M.; Lattuada, M.; Malfait, W.J. Strong, Machinable, and Insulating ChitosanUrea Aerogels: Toward Ambient Pressure Drying of Biopolymer Aerogel Monoliths. ACS Appl. Mater. Interfaces 2020, 12, 22037-22049. [CrossRef]

48. Van D Kerk, G.J.M. Linear Polyureas Prepared from Half-Polymers. U.S. Patent 3156672A, 10 November 1964. pp. 3-5.

49. Nitschke, C.; Scherr, G. Urea Derivatives. In Ullmann's Encyclopedia of Industrial Chemistry; Wiley-VCH Verlag GmbH \& Co. KGaA: Weenheim, Germany, 2010; Volume 11, pp. 1-9.

50. Gabler, R.; Müller, H. Preparation of Linear Polyureas Utilizing a Cyclic Amide Solvent. U.S. Patent 3185656A, 25 May 1965. pp. 1-2.

51. Markiewitz, K. US3763106A-Polymers Preapred by Reacting Urea with an Amino Alcohol or Diamine Followed by Methylolation with Formaldehyde. U.S. Patent 3,763,106, 1973.

52. Arnold, H.W. Process of Making Aliphatic Polyureas. U.S. Patent 2145242 A, 31 January 1939. p. 3.

53. Fleischer, A. Ueber Bildung von Azoverbindungen. Eur. J. Inorg. Chem. 1876, 9, 992-995. [CrossRef]

54. Baeyer, A. Mittheilungen aus dem organischen Laboratorium des Gewerbe-Institutes in Berlin: III. Notiz über die Einwirkung von Phenylsäure und Anilin auf Harnstoff. Eur. J. Org. Chem. 1864, 131, 251-253. [CrossRef]

55. Olin, J.F. Manufacture and Purification of Urea Derivatives. U.S. Patent 2,257,717, 30 September 1941.

56. Babu, S.S.; Shahid, M.; Gopinath, P. Dual palladium-photoredox catalyzed chemoselective C-H arylation of phenylureas. Chem. Commun. 2020, 56, 5985-5988. [CrossRef]

57. Chamni, S.; Zhang, J.; Zou, H. Benign synthesis of unsymmetrical arylurea derivatives using 3-substituted dioxazolones as isocyanate surrogates. Green Chem. Lett. Rev. 2020, 13, 246-257. [CrossRef]

58. Gezegen, H.; Gürdere, M.B.; Dinçer, A.; Özbek, O.; Koçyiğit, Ü.M.; Taslimi, P.; Tüzün, B.; Budak, Y.; Ceylan, M. Synthesis, molecular docking, and biological activities of new cyanopyridine derivatives containing phenylurea. Arch. Pharm. 2020, 354, e2000334. [CrossRef]

59. Ayyangar, N.R.; Chwodhary, A.R.; Kalkote, U.R.; Natu, A.A. A Non-phosgene Route for the Synthesis of Diethyldiphenylurea. Chem. Ind. 1988, 11, 599-600.

60. Arylureas II. Urea Method p-Ethoxyphenylurea. Org. Synth. 1951, 31, 11.

61. Jang, J.; Khanom, S.; Moon, Y.; Shin, S.; Lee, O.R. PgCYP76B93 docks on phenylurea herbicides and its expression enhances chlorotoluron tolerance in Arabidopsis. Appl. Biol. Chem. 2020, 63, 1-11. [CrossRef]

62. Wang, W.; Yang, P.; Guo, Y.; Ji, H.; Liang, F. Phenylurea herbicide degradation and N-nitrosodimethylamine formation under various oxidation conditions: Relationships and transformation pathways. Environ. Pollut. 2021, 269, 116122. [CrossRef]

63. Sharma, P.; Suri, C.R. Biotransformation and biomonitoring of phenylurea herbicide diuron. Bioresour. Technol. 2011, 102, 3119-3125. [CrossRef]

64. Hois, P.; Reichert, J. Bridged and Possibly Methylolized 4,5-bis-di-hydroxy-imidazolidin-2-ones, Process for Their Production and Use Thereof. WO1998005650A1, 12 February 1998.

65. Fischer, K.; Steimmig, A.; Bille, H.; Petersen, H.; Tulo, H. Manufacture of Easy-Care Finishing Agents for Cellulosic Textiles. U.S. Patent 3,996,178, 7 December 1976.

66. Ganesan, K.; Heyer, M.; Ratke, L.; Milow, B. Facile Preparation of Nanofibrillar Networks of "Ureido-Chitin" Containing Ureido and Amine as Chelating Functional Groups. Chem. Eur. J. 2018, 24, 19332-19340. [CrossRef]

67. Polino, D.; Parrinello, M. Kinetics of Aqueous Media Reactions via Ab Initio Enhanced Molecular Dynamics: The Case of Urea Decomposition. J. Phys. Chem. B 2019, 123, 6851-6856. [CrossRef]

68. Alexandrova, A.N.; Jorgensen, W.L. Why Urea Eliminates Ammonia Rather than Hydrolyzes in Aqueous Solution. J. Phys. Chem. B 2007, 111, 720-730. [CrossRef]

69. Ware, E. The Chemistry of the Hydantoins. Chem. Rev. 1950, 46, 403-470. [CrossRef]

70. Zarzyka-Niemiec, I. Products of reaction between $\mathrm{N}, \mathrm{N}^{\prime}$-Bis(2-hydroxyethyl)urea and ethylene carbonate and their application to obtain polyurethane foams. J. Appl. Polym. Sci. 2009, 114, 1141-1149. [CrossRef]

71. Schuster, F.; Ngamgoue, F.N.; Goetz, T.; Hirth, T.; Weber, A.; Bach, M. Investigations of a catalyst system regarding the foamability of polyurethanes for reactive inkjet printing. J. Mater. Chem. C 2017, 5, 6738-6744. [CrossRef]

72. Bernardini, J.; Licursi, D.; Anguillesi, I.; Cinelli, P.; Coltelli, M.-B.; Antonetti, C.; Galletti, A.M.R.; Lazzeri, A. Exploitation of Arundo donax L. Hydrolysis Residue for the Green Synthesis of Flexible Polyurethane Foams. BioResources 2017, 12, 3630-3655. [CrossRef]

73. Pilch-Pitera, B.; Kędzierski, M.; Olejnik, E.; Zapotoczny, S. Structure and properties of polyurethane-based powder clear coatings systems modified with hydrotalcites. Prog. Org. Coat. 2016, 95, 120-126. [CrossRef]

74. Simpson, S.S. Process for Manufacturing Poylurethane Using a Metal Acetyl Acetonate/Acetyl Acetone Catalyst System and the Product Made Therefrom. U.S. Patent 5,733,945, 31 March 1998.

75. Banihashemi, A.; Hazarkhani, H.; Abdolmaleki, A. Efficient and rapid synthesis of polyureas and polythioureas from the reaction of urea and thiourea with diamines under microwave irradiation. J. Polym. Sci. Part A Polym. Chem. 2004, 42, $2106-2111$. [CrossRef]

76. Sumner, J.B.; Hand, D.B.; Holloway, R.G. Studies of the intermediate products formed during the hydrolysis of urea by urease. J. Biol. Chem. 1931, 91, 333-341. [CrossRef] 
77. Jespersen, N.D. Thermochemical study of the hydrolysis of urea by urease. J. Am. Chem. Soc. 1975, 97, 1662-1667. [CrossRef] [PubMed]

78. Kappaun, K.; Piovesan, A.R.; Carlini, C.R.; Ligabue-Braun, R. Ureases: Historical aspects, catalytic, and non-catalytic propertiesA review. J. Adv. Res. 2018, 13, 3-17. [CrossRef] [PubMed]

79. Wlodarczyk, D.; Méricq, J.-P.; Soussan, L.; Bouyer, D.; Faur, C. Enzymatic gelation to prepare chitosan gels: Study of gelation kinetics and identification of limiting parameters for controlled gel morphology. Int. J. Biol. Macromol. 2018, 107, 1175-1183. [CrossRef] [PubMed]

80. Chenite, A.; Gori, S.; Shive, M.; Desrosiers, E.; Buschmann, M. Monolithic gelation of chitosan solutions via enzymatic hydrolysis of urea. Carbohydr. Polym. 2006, 64, 419-424. [CrossRef]

81. Krajewska, B.; Chudy, M.; Drozdek, M.; Brzózka, Z. Potentiometric Study of Urease Kinetics over pH 5.36-8.21. Electroanalysis 2003, 15, 460-466. [CrossRef]

82. Takeshita, S.; Zhao, S.; Malfait, W.J. Transparent, Aldehyde-Free Chitosan Aerogel. Carbohydr. Polym. 2021, 251, 117089. [CrossRef]

83. Tiwari, L.; Kumar, V.; Kumar, B.; Mahajan, D. A practically simple, catalyst free and scalable synthesis of N-substituted ureas in water. RSC Adv. 2018, 8, 21585-21595. [CrossRef]

84. Fujihara, A.; Shimada, N.; Maruyama, A.; Ishihara, K.; Nakai, K.; Yusa, S.-I. Preparation of upper critical solution temperature (UCST) responsive diblock copolymers bearing pendant ureido groups and their micelle formation behavior in water. Soft Matter 2015, 11, 5204-5213. [CrossRef]

85. Sharafi-Kolkeshvandi, M.; Nikpour, F. A facile and convenient approach for the one-pot synthesis of 2,4(1H,3H)-quinazolinediones. Chin. Chem. Lett. 2012, 23, 431-433. [CrossRef]

86. Welles, H.L.; Giaquinto, A.R.; Lindstrom, R.E. Degradation of Urea in Concentrated Aqueous Solution. J. Pharm. Sci. 1971, 60, 1212-1216. [CrossRef] 